6 Chapuy MC, Meunier PJ, Alexandre CM, Vigon GP. Effects of disodium dichloromethylene diphosphonate on the hypercalcemia produced by bone metastases. $\mathcal{7}$ Clin Invest 1980;65: $1243-7$

7 Hosking DJ, Cowley AJ, Bucknall CA. Rehydration in the treatment of severe hypercalcaemia. $Q$

8 Ralston SH, Fogelman I, Gardner MD, Boyle IT. Relative contribution of humoral and metastatic factors to the pathogenesis of hypercalcaemia in malignancy. Br Med f 1984;288:1405-8.

9 Hosking DJ, Gilson D. Comparison of the renal and skeletal actions of calcitonin in the treatment of severe hypercalcaemia of malignancy. Q Y Med 1984;53:359-68.

10 Ralston SH, Fogelman I, Gardner MD, Dryburgh SJ, Cowan RA, Boyle IT. Hypercalcaemia of malignancy: evidence for a non-parathyroid humoral agent with an effect on renal tubular handling of calcium. Clin Sci 1984;66:187-91.

11 Anonymous. Correcting the calcium [Editorial]. Br Med $\mathcal{f} 1977$;i:598

2 Peacock M, Robertson WG, Nordin BEC. Relation between serum and urinary calcium with particular reference to parathyroid activity. Lancet 1969;i:384-6.

13 Nordin BEC. Plasma calcium and plasma magnesium homeostasis. In: Nordin BEC, ed. Calcium, phosphate and magnesium metabolism. Edinburgh: Churchill Livingstone, 1976:186-202.

4 Mundy GR, Ibbotson KJ, D'Souza SM, Simpson EL, Jacobs JW, Martin TJ. The hypercalcemia of cancer. Clinical Kmplications and pathogenic mechanisms. N Engl f Med 1984:310:1718-27. ewart AF, Horst R, Deftos LJ, Cadman EC, Lang R, Broadus AE. Biochemical evaluation of patients with cancer-associated hyper
$N$ Engl f Med 1980;303:1377-87.

16 Agus S. Renal tubular transport of calcium: update. Adv Exp Med Biol 1978;103:37-49.
17 Suki WN. Calcium transport in the nephron. Am f Physiol 1979;237:F1-6.

18 Sleeboom HP, Bijvoet OLM, Van Oosterom AT, Gleed JH, O'Riordan JLH. Comparison of intravenous (3-amino-1-hydroxypropylidene)-1,1-bisphonate and volume repletion in tumour induced hypercalcaemia. Lancet 1983;ii:239-43.

19 Mundy GR, Martin TJ. The hypercalcemia of malignancy; pathogenesis and management. Meubolism 1982:31:1247-77.

20 Rodan SB, Insogna KL, Vignery AM-C, et al. Factors associated with humoral hypercalcemia of malignancy stimulate adenylate cyclase in osteoblastic cells. F Clin Invest 1983;72:1511-5.

1 Goltzman D, Stewart AF, Broadus AE. Malignancy associated hypercalcemia: evaluation with cytochemical bioassay for parathyroid hormone. F Clin Endocrinol Metab 1981;53:899-904.

22 Stewart AF, Insogna KL, Goltzman D, Broadus $\mathrm{AE}$. Identification of adenylate cyclas stimulating activity and cytochemical glucose-6-phosphate dehydrogenase-stimulating activity in extracts of tumors from patients with humoral hypercalcemia of malignancy. Proc Natl Acad Sci USA 1983;80:1454-8.

23 Fillastre JP, Humbert G, Leroy J. Treatment of acute hypercalcemia with furosemide. Curr Ther Res 1973;15:641-9.

24 Suki WN, Yium JJ, Von Linden M, Saller-Herbert C, Eknoyan G, Martinez-Maldonado Acute treatment of hypercalcemia with furosemide. $N$ Engl f Med 1970;283:836-40.

25 Sutuon RAL, Dirks JH. Renal handling of calcium phosphate and magnesium. In: Brenner BM, Rector FC, eds. The kidney. Philadelphia: Saunders, 1981:551-618.

\title{
Prospective study of attainment of social class of severely obese subjects in relation to parental social class, intelligence, and education
}

\author{
STIG SONNE-HOLM，THORKILD I A SØRENSEN
}

\begin{abstract}
Cross sectional population studies have shown that subjects who are severely obese are of lower social class than comparable subjects who are not obese. This may be ascribed to lower parental social class, poorer education, and lower intelligence test scores of the obese subjects. In this study based on 242633 draftees appearing before the draft board in Copenhagen between 1956 and 1977, 1144 extremely overweight men (body mass index $\geqslant 31 \mathrm{~kg} / \mathrm{m}^{2}$ ) were compared with 2123 young men randomly chosen from the remainder of the population. The two groups were followed up for an average period of 12.5 years, after which time their occupation was obtained from the National Population Register. Social class was derived from a ranking of occupations based on prestige from 0 (unskilled, manual worker) to 7 (for example, judge, professor). Among the obese subjects, only $\mathbf{3 0 0}$ $(30 \%)$ out of 1006 attained a position above social class 2 , compared with 988 (51\%) out of 1948 in the control group. At each level of education and intelligence test score, as registered at the draft board, the obese subjects still showed a significantly lower attainment of social class than the controls. Inclusion of parental social class, information which was available for part of the population, did not eliminate the difference in attainment of social class.

The results of this study show that obese subjects not only suffer from a higher risk of somatic diseases but have to live with a social handicap that is independent of parental social class, intelligence, and education.
\end{abstract}

Obesity Research Group, Department D 105, Herlev University Hospital, DK-2730 Copenhagen, Denmark

STIG SONNE-HOLM, MD, senior registrar

THORKILD I A SøRENSEN, MD, DMS, senior registrar

Correspondence and requests for reprints to: Dr S Sonne-Holm, L E Bruuns vej 27, DK-2920 Copenhagen, Denmark.

\section{Introduction}

Several studies have shown an inverse relation between obesity and social class, which is seen more strongly in women. ${ }^{1-4}$ A closer analysis of the nature of this relation requires prospective studies of factors related to social class. The social class of adults is positively correlated with parental social class, intelligence, and education. Several, possibly interacting, mechanisms may exert an influence on the correlation between obesity and social class. Population studies have shown that parents of obese adults have a lower attainment of social class than parents of non-obese adults ${ }^{167}$ and that obese subjects have lower intelligence, probably because of poorer education, than those who are not obese. ${ }^{68}$ It is not known, however, how far the lower attainment of social class of obese subjects may be attributed to lower parental social class, lower intelligence, and poorer education.

In this study we followed prospectively the attainment of social class of the most severely obese young men in a large draftee population and compared this with that of a randomly selected control group, taking into account parental social class, intelligence, and educational level.

\section{Subjects and methods}

In Denmark all men are registered with the military authorities at the age of 18 . Except for those who volunteer before this age $(2 \%)$, all are examined by the medical board within the next few years. The study population comprised 242633 men who had been examined by the board in the metropolitan area of Copenhagen from 1956 to 1977. To describe this population we drew a random $1 \%$ sample, numbering 2221 men, which was fewer than the 2426 expected as records were not available for those who were examined and found fit for service from 1958 to 1968 but who in 1969 were living in another region. Those found to be unquestionably unfit for service $(86(4 \%)$ out of 2221$)$ did not appear before the board. With few exceptions, the remaining men underwent systematic examination, including measurement of height and weight, intelligence testing, and rating of educational attainment.

We defined extreme overweight as a body mass index-that is, weight/ height ${ }^{2}$-of $\geqslant 31 \mathrm{~kg} / \mathrm{m}^{2}$, which is about $45 \%$ or more above the old insurance 
standards. ${ }^{9}$ We made a complete search of the files and found 1144 men who fulfilled the criterion for extreme overweight. The sample has been described in detail elsewhere. ${ }^{10}$

The control group was derived from the random sample drawn from the study population. ${ }^{11}$ After exclusion of the 86 men for whom no record of height and weight was available, in addition to 12 extremely overweight men who were already included in the obese group, the control group comprised 2123 men.

Social class was derived from the subjects' occupations taken from the annual income tax returns. By use of the National Population Register the occupational title of all subjects was obtained by 1 November 1980 . Social class was rated on an eight point scale from 0 (low: unskilled, manual worker-for example, cleaner, porter) to 7 (high: advanced professional positions-for example, university professor, judge) according to a modification of the scale described by Svalastoga, which was based on prestige in society. ${ }^{12}{ }^{13}$ Among the obese subjects information on five could not be retrieved from the register because they had died or emigrated before the register was established and 133 were pensioners or the record of their occupation was lacking. In the control group the corresponding numbers were 18 and 157, respectively. Students were rated according to their expected final level of education.

At the medical board the educational level had been recorded on a scale from 1 (primary school only (7 years)) to 9 (academic degree). The scale has been described in detail. ${ }^{8}$ This rating was available for $1115(98 \%)$ of the 1144 obese subjects and $2059(97 \%)$ of the 2123 controls. In the analysis levels 8 and 9 were pooled as level 9 could be attained only by passing level 8 (general certificate of education, advanced level (12 years)) and having the examination at the board postponed.

The draftees underwent a 45 minute paper and pencil intelligence test for groups, the Børge Priens test, the properties of which have been examined by Rasch. ${ }^{14}$ The test includes four subtests limited by time, covering broad aspects of cognitive functioning. The pencil score is the number of correct answers (out of 78). The test is still used at the board and is therefore not available to the public. The test method is well suited for evaluation of cognitive functions in population studies ${ }^{15} 16$ and showed a correlation of 0.77 with the Wechsler adult intelligence scale in 76 draftees re-examined after 5-10 years ( $\mathrm{T} W$ Teasdale and D R Owen, personal communication). Test results were available for $1114(97 \%)$ of the 1144 obese subjects and 2057 $(97 \%)$ of the 2123 controls and have been described in detail. ${ }^{68}$

Information on parental social class was available for draftees who were born after 1929 and had attended for any period of time the schools in the geographically well defined central municipality of Copenhagen. A systematic search of the school health records identified 365 (32\%) of the 1144 obese subjects and $666(31 \%)$ of the 2123 controls. According to the structure of these files, this rate of recovery corresponds to that expected from the geographical distribution of the population. The father's (or if not stated the mother's) occupation was recorded and rated on the same scale as that of their offspring.

Two different multivariate statistical analyses were used. The combined influence of the year of examination, intelligence test score, educational level, parental social class, and whether an obese or control subject on attainment of social class was carried out by logistic regression analysis. ${ }^{17}$ To examine possible effects of interactions between variables on social attainment log linear models for contingency tables were estimated. ${ }^{18}$

\section{Results}

Attainment of social class was poorer among the obese subjects. The group of unskilled manual workers (class 0 ) totalled $179(18 \%)$ among the 1006 obese subjects and $137(7 \%)$ among the 1948 controls. Among the obese

TABLE I-Attainment of social class of obese subjects $(n=1144)$ and controls $(n=2123)$

\begin{tabular}{cllcc}
\hline $\begin{array}{c}\text { Social } \\
\text { class }\end{array}$ & \multicolumn{1}{c}{ Type of work } & Example & $\begin{array}{c}\text { No } \% \text { of } \\
\text { obese subjects }\end{array}$ & $\begin{array}{c}\text { No (\%) of } \\
\text { controls }\end{array}$ \\
\hline 0 & Unskilled & Cleaner & $179(18)$ & $137(7)$ \\
1 & Semiskilled & Lorry driver & $162(16)$ & $155(8)$ \\
2 & Skilled & Bricklayer & $365(37)$ & $658(34)$ \\
3 & Subordinate clerk & Secretary & $111(11)$ & $292(15)$ \\
4 & Skilled with own business & . Farmer & $89(9)$ & $283(15)$ \\
5 & Subacademic professions & Schoolteacher & $37(4)$ & $185(10)$ \\
6 & Academic professions & Doctor & $63(6)$ & $236(12)$ \\
7 & Advanced professional positions & Professor & $0(0)$ & $2(0 \cdot 1)$ \\
\hline Total & & & $1006^{\star}(100)$ & $1948+(100)$ \\
\hline
\end{tabular}

* Social class unavailable in 138 subjects (five dead, 133 retired)

†Social class unavailable in 175 subjects ( 18 dead, 157 retired). subjects only $30 \%$ (300 out of 1006) exceeded social class 2 compared with $51 \%$ (998 out of 1948$)$ in the control group $(p<0.0001)$ (table I). Educational level and intelligence test score as well as parental social class were likewise poorer in the obese group $(\mathrm{p}<0.0007)$ (table II).

TABLE II-Educational level, intelligence test score, and parental social class of obese subjects $(n=1144)$ and controls $(n=2123)$

\begin{tabular}{lcc}
\hline & No $(\%)$ of obese subjects & No $(\%)$ of controls \\
\hline Educational level $^{\star}:$ & $193(17)$ & $129(6)$ \\
1 & $121(11)$ & $128(6)$ \\
2 & $121(11)$ & $136(7)$ \\
3 & $360(32)$ & $681(33)$ \\
4 & $32(3)$ & $115(6)$ \\
5 & $153(14)$ & $400(20)$ \\
6 & $25(2)$ & $76(4)$ \\
7 & $68(6)$ & $285(14)$ \\
9 & $42(4)$ & $109(5)$ \\
\hline \multirow{2}{*}{ Total } & $1115(100)$ & $2059(100)$ \\
\hline
\end{tabular}

Intelligence test score ${ }^{\star}$ :

\begin{tabular}{ccc} 
Intelligence test score $^{\star}:$ & $71(6)$ & $70(3)$ \\
$0-15$ & $120(11)$ & $111(5)$ \\
$16-21$ & $146(13)$ & $182(9)$ \\
$22-27$ & $241(22)$ & $323(16)$ \\
$28-34$ & $169(15)$ & $363(18)$ \\
$35-40$ & $170(15)$ & $386(19)$ \\
$41-46$ & $127(11)$ & $356(17)$ \\
$47-53$ & $48(4)$ & $194(9)$ \\
$54-59$ & $22(2)$ & $72(3)$ \\
$60-78$ & $1114(100)$ & $2057(100)$ \\
\hline Total & &
\end{tabular}

Parental social classt:

\begin{tabular}{ccc} 
Parental social classt: & & \\
0 & $109(30)$ & $139(21)$ \\
1 & $68(19)$ & $87(13)$ \\
2 & $95(26)$ & $202(30)$ \\
3 & $45(12)$ & $86(13)$ \\
4 & $36(10)$ & $107(16)$ \\
5 & $6(2)$ & $25(4)$ \\
6 & $6(2)$ & $17(3)$ \\
7 & & $3(0 \cdot 5)$ \\
\hline Total & $365(100)$ & $666(100)$
\end{tabular}

${ }^{\star}$ Educational level and intelligence test score were not available for roughly $2 \%$ of the population.

†Available only for draftees born after 1929 and who for any period of time attended the schools in the central municipality of Copenhagen.

Logistic regression analysis showed that the probability of exceeding social class 2 for obese subjects divided by the corresponding probability for the controls (odds ratio) was only $0 \cdot 40$, which is significantly different from 1 $(\mathrm{p}<0.0001 ;$ model I; taking into account the year of examination) (table III). Intelligence test score had a strong influence on attainment of social class $(p<0.0001)$, and after inclusion of this score in the model the odds ratio for obese subjects was 0.55 , which is still significantly lower than $1(p<0.0001)$ Educational level showed an effect on attainment of social class $(p<0.0001)$ that was independent of the intelligence test score. By including educational level in the model the odds ratio for obese subjects increased to 0.68 , also significantly different from $1(\mathrm{p}<0.0003)$.

The logistic regression analysis of subjects with known parental social class ( $n=941$; model II) showed largely the same pattern, though the difference in social class between obese and control groups was smaller (table III). Parental social class had a separate positive effect on attainment of social class $(\mathbf{p}<0.003)$. The odds ratio for the obese group was $0.83(\mathbf{p}<0.3)$, however, when the intelligence test score and educational level were included and increased to only $0.85(p<0.4)$ when parental social class was taken into account. When parental social class was included in the analysis as the first variable in model II the odds ratio for the obese group increased from 0.48 to $0.58(\mathrm{p}<0.0004)$.

To examine possible interactions between obese and control subjects, attainment of social class, intelligence test score, and educational level a log linear model for contingency tables was used that included a 16 class combined variable, comprising intelligence test score and educational level, and a 5 class social class variable. Analysis showed that in the model the relations could be explained by three two factor associations: the association of obese and control subjects with the combined variable; of obese and control subjects, with attainment of social class; and of the combined variable with attainment of social class. Thus the absence of a significant three factor interaction showed that the effect of obesity on the attainment of 
social class was not significantly dependent on the level of intelligence and education. Within each of the 16 levels of the combined variable of intelligence and education obese subjects attained a lower social class $(p<0.0001)$ (figure). In contrast with the logistic model there remained a significant relation between obese and control subjects and attainment of social class when parental social class was included in a combined variable together with intelligence test score and educational level $(\mathrm{p}<0 \cdot 011)$.

\section{Discussion}

This study shows that obese young men attain a lower social class than comparable non-obese men from the same population. Rated on a rank scale from 0 to 7 , only $30 \%$ of the obese subjects exceeded social class 2 compared with $51 \%$ of the control subjects. This difference could not be entirely accounted for by the lower parental social class was assessed, and we have therefore been able to analyse the prognostic impact of obesity on final social class. The longitudinal follow up of the subjects enables us to conclude that extreme overweight is followed by reduced attainment of social class.

In contrast with Goldblatt et $a l,{ }^{2}$ Garn et al found that among men studied in a total community sample from Tecumseh, Michigan $(n=845)$, higher education and income were associated with greater fatfold thickness. ${ }^{19}$ The investigation by Kohrs et al, based on a sample from Missouri $(n=259)$, showed an inverse relation between body mass index and income in men, whereas there was no correlation between body mass index and educational level..$^{20}$ These incongruous results might partly be explained by the fact that the random samples were small and the relation between social class and obesity was based on the average of fatfold thickness or relative weight in groups of subjects. Our study was of severely overweight subjects (body mass index $\geqslant 31 \mathrm{~kg} / \mathrm{m}^{2}$ ) - that is, the rightmost part

TABLE III-Coefficients ${ }^{\star}$ with standard errors in logistic regression analyses of social class attainment greater than level 2 after stepwise inclusion of determining variables

\begin{tabular}{|c|c|c|c|c|c|}
\hline & lst step & 2nd step & 3 rd step & 4th step & 5th step \\
\hline \multicolumn{6}{|c|}{ Model If } \\
\hline $\begin{array}{l}\text { Obese/control } \\
\text { Examination year } \\
\text { Intelligence test score } \\
\text { Educational level }\end{array}$ & $-0.927(\cdot 084)$ & $\begin{array}{r}-0.912(.085) \\
0.008(.007)\end{array}$ & $\begin{array}{r}-0.598(.096) \\
-0.051(.008) \\
0.100(.005)\end{array}$ & $\begin{array}{r}-0.382(.105) \\
-0.091(.009) \\
0.034(.006) \\
0.603(.036)\end{array}$ & \\
\hline \multicolumn{6}{|c|}{ Model II } \\
\hline $\begin{array}{l}\text { Obese/controls } \\
\text { Examination year } \\
\text { Intelligence test score } \\
\text { Educational level } \\
\text { Parental social class }\end{array}$ & $-0.741(\cdot 145)$ & $\begin{array}{l}-0.737(\cdot 148) \\
-0.002(\cdot 013)\end{array}$ & $\begin{array}{r}-0.363(\cdot 164) \\
-0.034(.014) \\
0.086(.007)\end{array}$ & $\begin{array}{r}-0.187(.175) \\
-0.064(.015) \\
0.033(.009) \\
0.504(.061)\end{array}$ & $\begin{array}{r}-0.162(\cdot 175) \\
-0.062(\cdot 016) \\
0.032(\cdot 009) \\
0.449(\cdot 064) \\
0.173(\cdot 057)\end{array}$ \\
\hline
\end{tabular}

*Odds ratio may be obtained as exponential function of coefficient. tObese subjects $n=984$; controls $n=1 \cdot 899$. fObese subjects $n=329$; controls $n=612$.

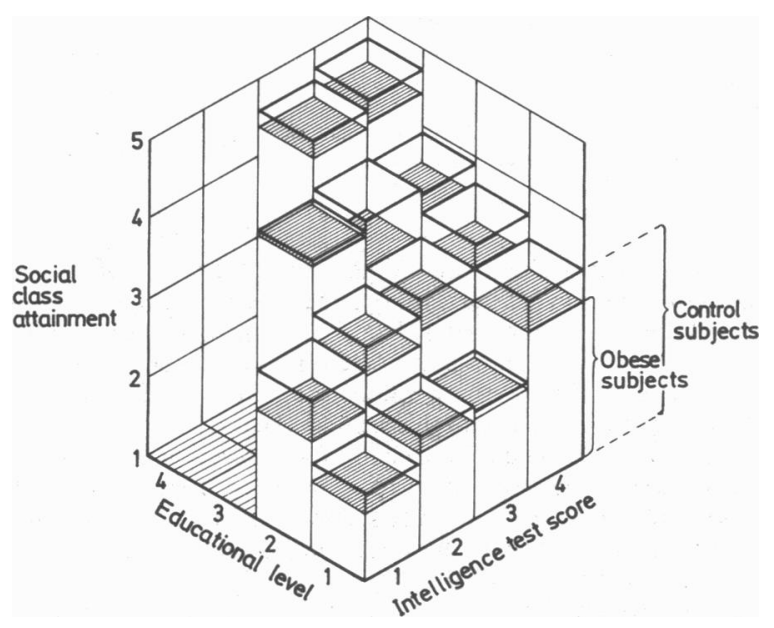

Social class attainment among 1006 extremely obese men and 1948 controls in relation to educational level and intelligence test score.

social class, intelligence test score, and educational level among the obese subjects.

In a cross sectional study of 1660 adults in Midtown, Manhattan, Goldblatt $e t$ al found that there was an inverse relation between obesity and socioeconomic state and that women who had attained a higher socioeconomic state relative to their fathers were less obese than women who had not. ${ }^{2}$ This finding was interpreted to indicate that social state depends in part on obesity and not vice versa. As socioeconomic state and body weight of the women were assessed at the same time the findings might also indicate that women moving upward in the social hierarchy lose weight.

The design of this study was prospective as the body mass index was recorded at the medical board examination before the final of the distribution of relative weight-in a much larger population of young men whose height and weight had been examined systematically.

The question arises how far can the attainment of lower social class of obese subjects, which occurs despite the factors closely related to social class, be attributed to the negative public attitude towards obesity, to personal psychosocial difficulties associated with obesity, or to an interaction of both? There is a more negative attitude towards obese subjects than handicapped and non-obese subjects, ${ }^{21.23}$ and those who are obese present with emotional disturbances that are similar to those seen among other victims of prejudice. ${ }^{24}$ The public attitude towards obese subjects might be founded on the general assumption that lack of self control (resulting in overeating) and lack of exercise are the causes of obesity. ${ }^{25}$ If this discrimination theory is correct we must try to change public attitudes towards obesity.

This study was supported by the Danish Heart Foundation. The data analyses were carried out using the SCIBAS system developed by the department of data processing, Herlev University Hospital, Copenhagen. We thank the Ministry of the Interior and the Psychological Service of the Danish Armed Forces for permission to use the draft board files and Knud A Sørensen for drawing the figure.

\section{References}

1 Moore ME, Stunkard AJ, Srole A. Obesity, social class, and mental illness. FAMA 1962;181: 138-42.

2 Goldblatt PB, Moore ME, Stunkard AJ. Social factors in obesity. FAMA 1965;192:1029-44.

3 Silverstone JT, Gordon RP, Stunkard AJ. Social factors in obesity in London. Practitioner 1969;202:682-8.

4 Noppa $\mathrm{H}$, Bengtsson C. Obesity in relation to socioeconomic status. A population study of women in Goteborg, Sweden. $\mathcal{I}$ Epidemiol Community Health 1980;34:139-42.

5 Jencks C. Inequality. New York: Basic Books, 1972.

6 Sørensen TIA, Sonne-Holm S, Christensen U, Kreiner SA. Reduced intellectual performance in extreme overweight. Hum Biol 1982;54:765-75.

7 Sørensen TIA, Sonne-Holm S, Christensen U. Cognitive deficiency in obesity independent of social origin. Lancet 1983;i:1105-6. 
8 Surensen TIA, Sonne-Holm S. Intelligence test performance in obesity in relation to educational attainment and parental social class. I Biosoc $S c i$ 1985;17:379-87.

9. Lew EA. New data on underweight and overweight persons. 7 Am Diet Assoc 1961;38:323-7.

10 Sonne-Holm S, Sørensen TIA. Post-war course of the prevalence of extreme overweight among Danish young men. $\mathcal{f}$ Chronic Dis 1977;30:351-8.

11 Christensen U, Sonne-Holm S, Sørensen TIA. Constant body mass index in Danish young men in 1943-1977. Hum Biol 1981;53:403-10.

12 Svalastoga K. Prestige, class and mobility. Copenhagen: Gyldendal, 1959.

13 Teasdale TA. Social class correlations among adoptees and their biological and adoptive parents Behav Genet 1979;9:103-14.

14 Rasch G. Probabilistic models for some intelligence and attainment tests. Chicago: University of Chicago Press, 1980.

15 Witkin HA, Mednick SA, Schulsinger F, et al. Criminality in XYY and XXY men. Science 1976; 193:547-55.

16 Teasdale TW, Owen DR. Heredity and familial environment in intelligence and educational level-a sibling study. Nature 1984;309:620-2

17 Walker SH, Duncan DB. Estimation of the probability of an event as a function of several independent variables. Biometrika 1967;54:167-79.
18 Bishop Y, Fienberg S, Holland P. Discrete multivariate analysis. Cambridge, Massachusetts: MIT Press, 1975.

19 Garn SM, Bailey SM, Cole PE, Higgens ITT. Level of education, level of income, and level of fatness in adults. Am $\mathcal{Y}$ Clin Nutr 1977;30:721-5.

20 Kohrs MB, Wang LL, Eklund D, Paulsen B, O'Neal R. The association of obesity with socioeconomic factors in Missouri. Am $\mathcal{F}$ Clin Nutr 1979;32:2120-8.

21 Wadden TA, Stunkard AJ. Adverse social and psychological consequences of obesity. Ann Intern Med 1985;103:1062-7.

22 Weiss E. Perceived self-infliction and evaluation of obese and handicapped persons. Percepl Mol Skills 1980;50:1268.

23 Canning H, Mayer J. Obesity-its possible effect on college acceptance abilities. N Engl f Med $1966: 275 \cdot 1172-4$

24 Monello LF Mayer J Obese adolescent girls. An unrecognized "minority" group? Am 7 Clin Nutr 1963;13:35-9.

25 Dejong $W$. The stigma of obesity: the consequences of naive asummption concerning the causes of physical deviance. I Health Soc Behav 1980;21:75-87.

(Accepted 10 December 1985)

\section{SHORT REPORTS}

\section{Rhythmic raiding of refrigerator related to rapid eye movement sleep}

We report on a patient who three to five times each night got out of bed and went to the adjacent kitchen to eat and drink, and correlate these episodes of eating with periods of rapid eye movement sleep.

\section{Case report}

A man aged 37 in a managerial job was concerned about the fact that he raided his refrigerator to eat and drink three to five times each night, about every one and a half hours.

When aged 1 he had received operations for epispadias, and his ureters had been implanted into the bowel. He first married at 23 years, but when the marriage broke down soon after his weight fell to $55 \mathrm{~kg}$. During the next few years he had an active sex life, and his nocturnal eating began. He remarried at 29 years to a woman with a keen interest in cooking. His wife was unperturbed by his nocturnal activities and generally slept through them. If she spoke as he got out of bed he would only mutter back, and she did not think that he was properly awake as often in the morning he would not remember having got up during the night. After each episode of eating he would rapidly fall back to sleep. Sometimes he would switch on the kitchen light, and sometimes he would behave oddly-for example, he had once found himself drinking sunflower oil. Asked why he did not simply restrain himself and stay in bed, he said that it was "a sort of impulsion." When he and his wife went to France each summer for a month they would place food and drink beside his bed every night.

During the past 12 years he had regularly taken cycloserine to prevent urinary tract infections. He had also been told to drink plentifully. His nocturnal behaviour did not seem to have the characteristics of sleepwalking, but as sleepwalking can be provoked by drugs acting on the central nervous system the cycloserine treatment was suspected. Treatment with trimethoprim instead of cycloserine had no effect on his nocturnal behaviour. Generally, he was healthy, but his blood urea was $9.6 \mathrm{mmol} / 1(85 \mathrm{mg} / 100 \mathrm{ml})$ and he had mild renal scarring. His height was $172 \mathrm{~cm}$, and his weight improved steadily when he started to live with his second wife, becoming stable at about $70 \mathrm{~kg}$ for the past several years. There was no history of abnormal daytime eating habits or any unusual concern for his body size. His hobbies were mainly sedentary.

He spent six nights in the sleep laboratory and would put beside his bed two bottles of soft drink, a pork pie, several packets of potato crisps, and biscuits. He fell asleep quickly and slept on average for 439 minutes with a normal distribution of sleep stages, including $25 \%$ rapid eye movement (paradoxical) sleep. There were 31 episodes of eating, counting closely grouped eating episodes as one; 28 of these occurred just before, in the middle of, or just after a period of rapid eye movement sleep (figure). An electroencephalogram confirmed brief wakefulness as each eating and drinking episode began, and a video tape showed him unscrewing and screwing up bottle tops. While chewing, however, he would be falling asleep and would pass into stage 2 sleep within a few seconds and rapid eye movement sleep within half a minute.

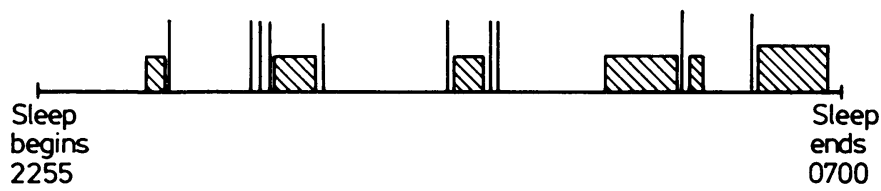

Episodes of eating and drinking in relation to rapid eye movement sleep during the night (measured in the sleep laboratory). Hatched areas are periods of rapid eye movement sleep; lines are episodes of eating.
The patient and his wife agreed that when they next went on holiday they would not have any food by the bedside. On return he claimed to have had only soft drinks during the night. His nocturnal eating returned, however, and at follow up at one year he was again raiding the refrigerator every hour and a half during the night. He now dismissed it cheerfully, saying that it did not affect him adversely.

\section{Comment}

In their early description of periods of rapid eye movement in the sleep of babies on demand feeding, Aserinsky and Kleitman reported that demands for food were related in time to rapid eye movement sleep. ${ }^{\prime}$ In adults there is a 100 minute rhythm in waking behaviour, as is the case with periods of rapid eye movement during sleep, and, in an unstructured environment, waking adults tend to eat and drink spontaneously every 100 minutes. ${ }^{23}$

In conclusion, our patient exhibited a normal propensity for rhythmic eating and drinking but was unusual in not suppressing this at night as most adults do.

Aserinsky, E, Kleitman N. A motility cycle in sleeping infants as manifested by ocular and gross bodily activity. I Appl Physiol 1955;8:11-8.

Friedman $S$, Fisher $C$ On the presence of a rhythmic, diurnal, oral instinctual drive cycle in man $\gamma$ Am Psychoanal Assoc 1967;15:317-43.

3 Oswald I, Merrington J, Lewis L. Cyclical "on demand" oral intake by adults. Nature 1970;225:959-60.

(Accepted 8 November 1985)

University Department of Psychiatry, Royal Edinburgh Hospital, Edinburgh EH10 5HF

IAN OSWALD, MD, FRCPSYCH, professor of psychiatry

KIRSTINE ADAM, PHD, research fellow

Correspondence to: Professor Oswald.

\section{Cyanosis attributable to right to left shunt in the carcinoid syndrome}

Cyanosis is commonly observed in the carcinoid syndrome and thought usually to be due to haemostasis in dilated capillaries. ${ }^{1}$ We present a case in which central cyanosis appeared to be secondary to a pronounced right to left shunt.

\section{Case report}

A 69 year old woman presented with weight loss, diarrhoea, ankle swelling, and exertional dyspnoea of six months' duration. She had previously been fit, was a non-smoker, and was not taking any drugs. On examination she was thin, centrally cyanosed (but not clubbed), and breathless on minimal exertion. She had sinus tachycardia (100 beats/min), a soft ejection systolic murmur at the upper left sternal edge, and moderate ankle oedema. Jugulovenous pressure was not raised. There were no signs of chronic liver disease, and the liver was not palpable. A firm mass the size of a golfball was felt in the right iliac fossa. 